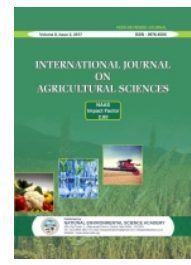

\title{
PESTICIDE RESIDUES IN MARKET SAMPLES OF VEGETABLES
}

\author{
Jitendra Prasad and Pammi Kumari \\ P.G. Department of Zoology \\ Samastipur College, Samastipur, Bihar
}

\begin{abstract}
The presence of pesticide residues in food commodities has always been a matter of serious concern. Farmers apply pesticides repeatedly to ward off the pest and pick the vegetables at short intervals. The samples of vegetables were collected from market in three blocks of Samastipur district purposively as per multistage random sampling design to monitor the residues in market vegetables. GC-MS analysis was applied for evaluation of pesticide residues in the sample. The data obtained so far showed that out of 50 samples of vegetable analyzed 24 (48\%) were contaminated with different pesticides and 3 samples (6\%) samples contained residues above MRL. The overall pesticide occurrence was in the order as Endosulphan $>$ Quinalphos $>$ Dimethoate $>$ Chlorpyriphos $>\alpha$-HCH $>\delta$-HCH $>\beta$-HCH. Pesticide contamination was higher in cabbage than cauliflower.
\end{abstract}

Keywords: Cabbage, Samastipur,GC-MS Analysis, Vegetarian Population, Residues.

\section{INTRODUCTION}

Indian population is exposed to very high levels of pesticide residues in numerous ways. The problem is especially serious when these commodities present in food. Vegetables are staple food items in Indian population. A sizeable section of our society is vegetarian. India is the second largest producer of vegetables. Copious quantities of residues have been observed in fruits and vegetables. Monitoring of farmgate samples of vegetables collected from different locations in India showed the contamination level to the extent of 73 per cent with varying levels of pesticide residues (Madan et al. 1996; Awasthi et al. 1997; Chahal et al. 1997; Shah et al. 2000; Kole et al. 2002; Deka et al. 2005). Many a times, the extent of residues is above the prescribed MRL. Nearly, 40 to 60 percent of market samples of vegetables analysed across the country has been observed contaminated with pesticide residues (Handa, 1992). The presence of the residues which are highly toxic and hard to degrade such as
DDT \& HCH make the situation more alarming (Srivastav and Patel, 1990). However, there has been wide variation in level of contamination in different vegetables. The vegetables crops are grown all over in the country. However, Bihar state is third largest producer of vegetables in the country. The total area under vegetable cultivation is currently about $11 \%$ of the state's gross sown area, and is rapidly increasing. The important vegetable crops include potato, onion, tomato, cauliflower and brinjal. Production of vegetables is well dispersed over the districts, with a concentration of production in some particular districts. The total area under vegetables crops is 4.90 lakh ha with total annual production of 7.5 lakh MT.

Farmers apply pesticides repeatedly to ward off the pest and pick the vegetables at short intervals. Thus, there is always a probability that vegetables sent to market contain high content of pesticide residue. The present study was undertaken to monitor the residues in market vegetables of Samastipur district of Bihar state.

*Corresponding author: ansu356@gmail.com 


\section{MATERIAL \& METHODS}

The samples of vegetables were collected from three blocks viz. Hasanpur, Sarairanjan and Jitwarpur of Samastipur district purposively as per multistage random sampling design. Five samples of each of the selected vegetables (Cabbage \& Cauliflower) were collected. In this way, each year a total of 20 samples were brought to the laboratory and were subjected to analysis for pesticides by multiresidue method.

Samples consisted of 1-2 kg of each vegetable comprising cauliflower and cabbage. It were cut into small pieces and homogenized. $15 \mathrm{~g}$ of homogenate was put into a polytetrafluoroethylene (PTFE) tube and mixed successively with $15 \mathrm{ml}$ of acetonitrile containing $1 \%$ acetic acid (v/v), 6 g MgSO4 and 2.5 g sodium acetate trihydrate (equivalent to $1.5 \mathrm{~g}$ of anhydrous form). The mixture was shaken thoroughly and kept in ice bath. The samples were then centrifuged at $4000 \mathrm{rpm}$ for $5 \mathrm{~min}$ and 6 $\mathrm{ml}$ of the supernatant were transferred to a $15 \mathrm{ml}$ PTFE tube to which $900 \mathrm{mg} \mathrm{MgSO} 4$ and $300 \mathrm{mg}$ PSA were added. The extract was shaken using a vortex mixer for $20 \mathrm{~s}$ and centrifuged at $4000 \mathrm{rpm}$ again for $5 \mathrm{~min}$, approximately $2 \mathrm{ml}$ of the supernatant were taken in a vials. This extracts were evaporated to dryness under a stream of nitrogen and reconstituted in n-hexane in auto sampler tube for the GCMS analysis. Standard preparation For preparation of stock solution, standards were dissolved in ethyl acetate and four levels of intermediate standard solution of each pesticide were prepared maintaining the same matrix concentration for the preparation of calibration curve and stored at $-40{ }^{\circ} \mathrm{C}$ in the dark. Working solutions were prepared daily by appropriate dilution with ethyl acetate. Instrumentation GC-MS analysis was performed with a Varian 3800 gas chromatograph with electronic flow control (EFC) and fitted with a Saturn 2200 ion-trap mass spectrometer (Varian Instruments, Sunnyvale, CA, USA). The computer that controlled the system also held a GC-MS library specially created for the target analytes under our experimental conditions. The mass spectrometer was calibrated weekly with perfluoro-tributylamine. Helium (99.99\%) at a flow-rate of $1 \mathrm{ml}$ min- 1 was used as carrier and collision gas.

\section{RESULT \& DISCUSSION}

The occurrence of pesticidal compounds in the food chain has already been reported in several studies (Tiwari et al. 2019). Cabbage \& Cauliflower are major vegetables grown

Table 1: Pesticide Residues ( $\mathrm{mg} \mathrm{kg}^{-1}$ ) in Vegetable samples.

\begin{tabular}{|l|c|c|}
\hline Pesticide & Cabbage & Cauliflower \\
\hline$\alpha-\mathrm{HCH}$ & ND & 0.005 \\
\hline$\beta-\mathrm{HCH}$ & 0.006 & ND \\
\hline$\delta$-HCH & 0.005 & 0.007 \\
\hline P,P'DDE & 0.006 & ND \\
\hline P,P'DDD & ND & ND \\
\hline P,P'DDT & 0.006 & 2.870 \\
\hline Endosulfan & 0.312 & 0.057 \\
\hline Chlopyriphos & 0.021 & 0.031 \\
\hline Quinolphos & 0.024 & ND \\
\hline Dimethoate & ND & ND \\
\hline
\end{tabular}

Table 2: Monitoring of Pesticide residues in vegetable (Crop wise).

\begin{tabular}{|l|c|c|c|c|}
\hline Crop & Number of Samples & $\begin{array}{c}\text { Range of residues } \\
\left.\text { detected (mg kg } \mathbf{~}^{-1}\right)\end{array}$ & $\begin{array}{c}\text { Number of } \\
\text { Samples above } \\
\text { MRL (\%) }\end{array}$ \\
\hline Cabbage & Analysed & Contaminated (\%) & & \\
\hline Cauliflower & 10 & $7(70 \%)$ & $0.005-0.312$ & nil \\
\hline
\end{tabular}


Table 2: Monitoring of Pesticide residues in vegetable (Crop wise).

\begin{tabular}{|l|c|c|c|c|}
\hline Crop & \multicolumn{2}{|c|}{ Number of Samples } & $\begin{array}{c}\text { Range of residues } \\
\text { detected (mg kg } \mathbf{~}^{-1}\end{array}$ & $\begin{array}{c}\text { Number of } \\
\text { Samples above } \\
\text { MRL (\%) }\end{array}$ \\
\hline$\alpha-H C H$ & Analysed & Contaminated (\%) & \\
\hline$\beta-H C H$ & 5 & $3(60 \%)$ & $0.005-0.006$ & nil \\
\hline$\delta$-HCH & 5 & $3(60 \%)$ & $0.005-0.006$ & nil \\
\hline P,P'DDE & 5 & $3(60 \%)$ & $0.005-0.007$ & nil \\
\hline P,P'DDD & 5 & $1(10 \%)$ & 0.005 & nil \\
\hline P,P'DDT & 5 & $1(10 \%)$ & 0.005 & nil \\
\hline Endosulfan & 5 & $1(10 \%)$ & 0.006 & $2(40 \%)$ \\
\hline Chlopyriphos & 5 & $5(100 \%)$ & $0.315-2.870$ & nil \\
\hline Quinalphos & 5 & $2(40 \%)$ & $0.021-.057$ & $1(20 \%)$ \\
\hline Dimethoate & 5 & $4(80 \%)$ & $0.024-1.04$ & nil \\
\hline
\end{tabular}

on commercial scale. The vegetables were analysed for organochlorine and organophosphate pesticides such as p,p'DDT, p,p'DDD, p,p'DDE, $\alpha-\mathrm{HCH}, \beta-\mathrm{HCH}, \delta-\mathrm{HCH}$, Endosulfan, Chlorpyriphos, Quinalphos, \& Dimethoate (Table 1). The data obtained so far showed that out of 50 samples of vegetable analyzed 24 (48\%) were contaminated with different pesticides and 3 samples (6\%) samples contained residues above MRL. The overall pesticide occurrence was in the order as Endosulphan $>$ Quinalphos $>$ Dimethoate $>$ Chlorpyriphos $>\alpha-\mathrm{HCH}>\delta$ $\mathrm{HCH}>\beta-\mathrm{HCH}$. None of the sample was found containing DDT, DDD or DDE. Pesticide contamination was higher in cabbage than cauliflower.

Among the samples of Cabbage, 7 samples (70\%) out 10 analyzed were contaminated with $\beta-\mathrm{HCH}\left(0.006 \mathrm{mg} \mathrm{kg}^{-1}\right)$, $\delta$-HCH (0.005 mg kg $\left.{ }^{-1}\right)$, p,p' DDE ((0.007 mg kg $\left.{ }^{-1}\right)$,DDT $\left(0.007 \mathrm{mg} \mathrm{kg}^{-1}\right)$ Endosulfan (0.312 $\left.\mathrm{mg} \mathrm{kg}^{-1}\right)$, Quinolphos (0.024 mg kg $\mathrm{kg}^{-1}$ \& Chlorpyriphos (0.021 mg kg-1). Dimethoate could not be detected. However none of the residues detected so far were above MRL. Whereas, in the case of Cauliflower, $50 \%$ of the samples were found containing residues. These were the residues of $\alpha-\mathrm{HCH}$ (0.005 mg kg ${ }^{-1}$ ), $\delta$-HCH (0.005 $\left.\mathrm{mg} \mathrm{kg}^{-1}\right)$, Endosulfan (2.870 $\mathrm{mg} \mathrm{kg}{ }^{-1}$ ), Quinolphos (0.031 $\mathrm{mg} \mathrm{kg}^{-1}$ ), \& Chlorpyriphos $\left(0.057 \mathrm{mg} \mathrm{kg}^{-1}\right)$. Presence of endosulfan residue was higher than the MRL value.

The results are almost similar to those reported with the contamination levels in India (Kumari et al. 2003) and world (Hjorth et al. 2011). In 94\% of Market vegetables samples, residues were found below MRL, while $6 \%$ of market vegetable samples, residues are above the MRL (PFA 1954).

The study indicates the use of lindane as well as technical formulation of the $\mathrm{HCH}$ in the study area and, contamination of these vegetables with DDTs. This may be due to transportation of pollutants from nearby human settlement areas, where pesticides used for public health aspects. The data of this study shows that the $\mathrm{\Sigma HCH}$ levels in vegetables in this study were lower than vegetables from Kanpur, India (Hans et al. 2000) Agra, India (Bhanti \& Taneja 2005), Meerut, Muzaffarnagar and Ghaziabad districts of Uttar Pradesh, India (IPEN 2006),Haryana, India and cities of Central Uttar Pradesh, India. A much higher contamination of vegetables with $\mathrm{\Sigma HCH}$ compared with a MRL of $50 \mu \mathrm{g}$ kg-1 was reported in vegetables from Kanpur, India, Hissar, India. Though endosulfan was banned for its agricultural use the presence of its residues in recent samples indicated its illegal use which might be from previous stock. Multiple residues were higher in cabbage than cauliflower.

\section{CONCLUSION}

Concentrations of various pesticides were well below the tolerances but continuous consumption of such vegetables even with moderate contamination level may accumulate in receptor's body and may prove fatal for human population in the long term. 


\section{REFERENCES}

1. Awasthi, M.D., Sharma, D. and Ahuja, A.K. (1997) Occurrence of pesticide in market and farmgate samples of vegetable in and around Bangalore. Journal of Food Science \& Technology. 34: 146-149.

2. Bhanti, M. and Taneja, A. (2005) Contamination of vegetables of different seasons with organophosphorus pesticides and related health risk assessment in northern India. Chemosphere 69(1): 63-68.

3. Chahal, K.K., Singh, B., B.K., Battu, R.S. and Joia, B.S. (1997). Insecticide residues in farm gate vegetable samples in Punjab. Pesticide Research Journal. 9 (2): 256-260.

4. Deka, S.C., Berman, N. and Baruah, A.A.L.H. (2005) Pesticidal contamination status in farm gate vegetables in Assam, India. Pesticide Research Journal. 17 (2): 90-93.

5. Handa, S.K. (1992). Monitoring of pesticide residues in Indian Environment. Pest management and pesticides-Indian Scenario. Ed. B.V. David, Namratha Publication, Madras (India): pp.221-224.

6. Hans, Y., Sherman, D. M., Linton, R. H., Nielsen, S. S., \& Nelson, P. E. (2000). The effects of washing and chlorine dioxide gas on survival and attachment of Escherichia coli O157: H7 to green pepper surfaces. Food Microbiology, 17(5):521- 533.

6. Hjorth K., K. Johansen, B. Holen, A. Andersson, H.B. Christensen, K. Siivinen (2011) Pesticide residues in fruits and vegetables from South America - a Nordic project Food Control, 22: 1701-1706.

7. Kole. R.K., Banerjee, H. and Bhatacharya, A. (2002). Monitoring of pesticide residues in farm gate vegetable samples in West Bengal. Pesticide Research Journal.14 (1): 77-82.

8. Kumari, B., Kumar, R., Madan, V.K., Singh R., Singh, J. and kathpal, T.S. (2003). Magnitude of pesticidal contamination in winter vegetables from Hisar, Haryana. Environmental Monitoring and Assessment. 87 (3): 311-318.

9. Madan, V.K., Kumari, B., Singh, R.V., Kumar, R. and Kathpal, T.S. (1996). Monitoring of pesticides from farm gate samples of vegetables in Haryana. Pesticide Research Journal. 8 (1): 56-60.

10. Shah, P.G., Raj, M.F., Patel, B.K., Diwan, K.D., Patel, J.A. and Talati, J.G. (2000). Pesticidal contamination status in farm gate vegetables in Gujarat. Pesticide Research Journal. 12(2): 195-199.

11. Srivastav, U.K. and Patel, N.T. (1990). Pesticide residues in foods-Present situation. In: Pesticide industry in India-CMA Monograph, No.142, Oxford \& IBH Publications: pp.89-105.

12. Tiwari A. , Rastogi A., Singh V. and Arunachalam A. (2019) Water stress effects on nutritional values and relative water content of barnyard and finger millet crops. International Journal on Agricultural Sciences. 10 (1): 23-28. 